\title{
Modernidade, identidade e suicídio: o "judeu" Stefan Zweig e o "mulato" Eduardo de Oliveira e Oliveira
}

\begin{abstract}
Monica Grin
"Se isso é verdade, a história do mundo é a história, não de individuos, mas de grupos, não de nações, mas de raças

W.E.B. Du Bois, 1897

"Holocaust survivor Konrad Latte, whose story was told recently in the New York Times Magazine, shocked Israeli journalists when he told them that he did not consider himself to be a Jew. His only felt connection to Jewishness was to have been persecuted as a Jew. He did not want to grant Hitler the authority to determine his identity, to tell him with whom to associate even in the wake of the Shoah: "I can't let the Nazis have the last word. I can't let them tell me, 'You are a Jew, you belong in this corner, this drawer'".
\end{abstract}

David Hollinger, 1999

\section{Introdução}

$\mathrm{O}$ objetivo deste ensaio é sugerir um contraste entre os dilemas de identidade da modernidade do contexto europeu, cuja premissa classificatória se pauta pelo mal-estar da "condição ambivalente" ante o ideário nacionalista, ${ }^{1}$ e os dilemas de identidade da "modernidade brasileira", que, contrariamente, reificam e naturalizam a ambivalência em sua expressão étnico-racial, como "marca" de identidade nacional. Trata-se de uma reflexão sobre os limites da universalidade do projeto moderno de emancipação e assimilação dos judeus nos séculos XIX e XX, bem como dos negros em sociedades pós-escravistas. ${ }^{2}$

Sugiro, neste ensaio, que a construção simbólica da ambivalência racial presente na modernidade brasileira, sobretudo a partir dos anos 1930, ${ }^{3}$ 
não apenas promove um contradiscurso alternativo ao purismo racialista presente nos contextos europeu e norte-americano, mas abriga também uma dimensão sociológica perversa.

Dois personagens suicidas, o escritor "judeu” Stefan Zweig e o sociólogo "mulato" Eduardo de Oliveira e Oliveira, trágicos por razões opostas, serão aqui considerados como exemplos de deslocamentos identitários produzidos quer pelo imperativo moderno da não-ambivalência, quer pela reificação da ambivalência ou, se preferirmos, da mistura racial. Pretendese propor que os dois casos representam, in extremis, expressões de libertação aos desafios impostos por diferentes imperativos identitários e que o entendimento da dinâmica racial no contexto brasileiro impõe-se, comparativamente, como importante chave para uma melhor compreensão das antinomias da modernidade.

Os diálogos comparativos entre processos de emancipação e assimilação em diferentes contextos vêm mobilizando recentemente maiores esforços analíticos ${ }^{4}$ — especialmente por deslocarem o foco de entendimento da modernidade em suas construçôes de raça, nacionalidade e identidade étnica, de uma perspectiva unilinear, generalizada e ubíqua, para uma perspectiva na qual respostas culturais alternativas são construídas socialmente sob o impacto de uma agenda comum de questôes. Não se trata da velha oposição entre tradição e modernidade, entre atraso e modernização, ou entre hierarquia e igualdade. Trata-se de entender os arranjos simbólicos, as acomodaçôes imaginativas e as mesclas de diferentes valores e projetos individuais e sociais que a modernidade em suas versões locais incita.

\section{A tragédia de Stefan Zweig}

Fevereiro de 1942. O famoso escritor Stefan Zweig, "europeu-austríaco-judeu”, suicida-se com sua mulher Charlotte em Petrópolis. Curiosamente o faz em país por ele considerado o último refúgio para os perseguidos do racialismo ariano, paraíso da ambivalência, ou país dos contrastes em precioso equilíbrio, como ele definia o Brasil em seu polêmico Brasil, Pais do Futuro, ${ }^{6}$ de 1941.

O que separa com hostilidade e desconfiança nos outros países, aqui se combina livremente. Quantas raças encontramos nas ruas: o preto de casaco roto, 
o europeu com terno bem talhado, o caboclo de olhar grave e cabelos pretos e lisos; em centenas e milhares de matizes, as mesclas de todos os povos e de todas as nacionalidades: mas todos não como em Nova York ou em outras cidades, separados em bairros, aqui negro, ali brancos, acolá mestiços, mais adiante italianos, irlandeses ou japoneses. Todos aqui se misturam, e a rua, pela grande variedade das fisionomias, se torna um quadro constantemente cambiante. Que habilidade se torna necessária aqui para atenuar os contrastes, sem destruí-los, para conservar a variedade sem a preocupação de ordená-la e organizá-la à força! Que essa cidade conserve tal habilidade! Que não seja acometida do delírio geométrico das avenidas retas, dos nítidos cruzamentos, da horrenda idéia da excessiva regularidade das modernas cidades grandes, que sacrificam à simetria da linha e à monotonia das formas, precisamente o que é sempre o incomparável de toda cidade: suas surpresas, seus caprichos e suas angulosidades e sobretudo seus contrastes entre o velho e o novo, entre a cidade e a natureza, entre rico e pobre, entre trabalhar e flanar, contrastes que aqui se gozam em sua harmonia. ${ }^{7}$

As ambições totalizadoras do projeto moderno que assolaram a Europa, sobretudo sob os fascismos, com seus princípios de ordem, de classificação, de taxonomia e de identificação de grupos e indivíduos, tiveram para Stefan Zweig sabor amargo e trágico. ${ }^{8}$ Classificado como "judeu”, nos modos da obsessão racialista, quando não necessariamente pautava seus interesses, valores, cultura, língua, crença e identidade segundo apenas esse marcador identitário, Zweig viu-se excluído do ambiente europeu, particularmente o de língua alemã, que ele, como muitos outros “judeus” de sua geração, acreditava se tratar de civilização vocacionada para o cosmopolitismo, expressão de culturas sem fronteiras rígidas, lugar de acolhimento e de universalismo.

Diante do obstáculo racista europeu, sobretudo sob o nazismo, o Brasil funcionaria para Stefan Zweig como uma espécie de utopia de mundo "desracializado", "paraíso" dos que se querem sem lugar racial fixo. A plasticidade e a estética do "povo" brasileiro, capturadas pela sensibilidade do "refugiado", produziriam neste autor acalento simbólico mais do que propriamente sociológico, e um vislumbre de que a "civilização" no Brasil exercitaria, ao contrário da européia, a arte dos contrastes, da mistura e da tolerância. Todavia, ele se mata no Brasil. 
No quarto em que ele se suicidou com sua mulher Charlotte, foi encontrada uma carta, escrita em alemão, intitulada, em português, "Declaração", na qual ele se justificava para os amigos e se despedia do Brasil:

Antes de deixar a vida por minha livre e espontânea vontade e em pleno domínio de minhas faculdades, sinto-me impelido a cumprir uma última obrigação: fazer um sincero agradecimento a esta esplêndida terra do Brasil, que proporcionou a mim e ao meu trabalho um repouso tão generoso e hospitaleiro. Meu amor por este país aumentou dia após dia, e em nenhum outro lugar eu teria preferido reconstruir uma vida nova, hoje que o mundo da minha língua desapareceu para mim e que meu lar espiritual, a Europa, destruiu a si mesmo. Mas, depois de sessenta anos, é preciso ter uma força incomum para fazer um começo inteiramente novo. A que possuo esgotouse nos longo anos de perambulação sem teto. Assim, julgo melhor concluir, em tempo hábil e de cabeça erguida, uma vida na qual o trabalho intelectual representou a mais pura alegria, e a liberdade pessoal, o bem mais precioso da Terra. Saúdo todos os meus amigos! Possam eles ter a graça de ain$\mathrm{da}$ ver a alvorada depois da longa noite! Eu, impaciente demais, sigo na frente. ${ }^{9}$

\section{A trajédia de Eduardo de Oliveira e Oliveira}

São Paulo, 1980. O sociólogo Eduardo de Oliveira e Oliveira, ${ }^{10 ~ " m u-~}$ lato e brasileiro", é encontrado morto em seu apartamento em completo estado de inanição auto-infligida. ${ }^{11}$ Reconhecido pelos seus colegas como talentoso e polêmico, Eduardo de Oliveira e Oliveira deixou parco material escrito, uma peça de teatro encenada e morreu praticamente desconhecido. $^{12}$

No país da "mestiçagem", da "ambivalência” racial, da "mulatice", não haveria lugar para os que desejam a solidez de uma identidade pura, definida e diferenciada. No país das mesclas, não convém ser só "negro", ou só "branco". O mulato que é regra, que é normalidade no Brasil miscigenado, representa para Eduardo de Oliveira e Oliveira, o trânsfuga - metáfora de indeterminação, de indefinição em mundo para ele mais do que racialmente diferenciado, racialmente desigual. Para este sociólogo, o mulato é o "obstáculo epistemológico", a barreira simbólica que impede a clareza de 
um mundo social cuja história de escravidão e opressão dos não-brancos deveria revelar-se determinada por critérios de pertencimento "racial". Em chave política, para este sociólogo, o mulato é o traidor dos pólos "branco" e "negro"; é quem ameniza, desqualifica e dilui a consciência e o conflito raciais.

Conta-se que Eduardo de Oliveira e Oliveira repetia freqüentemente uma frase que seu pai, um dirigente sindical, sussurava ao seu ouvido quando passeavam de carro pelo cais do porto do Rio de Janeiro: "Não se esqueça nunca meu filho: tudo que você é, ou poderá ser, deve a essa negrada", referindo-se aos estivadores do cais do porto, em sua maior parte negros. ${ }^{13}$

Em seu mais conhecido trabalho, "O Mulato, Um Obstáculo Epistemológico", ${ }^{14}$ na verdade uma resenha crítica ao livro de Carl Degler, Neither Black, Nor White, ${ }^{15}$ de 1971, Eduardo de Oliveira e Oliveira expressa toda sua discordância e mal-estar em relação à proeminência com que o mulato, "válvula de escape", aparece na argumentação de Degler a propósito das relações raciais no Brasil comparadas aos Estados Unidos. Ao final de sua crítica a Degler, referindo-se a Franz Fanon, ${ }^{16}$ assim ele conclui:

Mas, afinal, o que todos os homens negros, além do fato de terem deixado a África (ou terem ficado lá), têm realmente em comum? Perguntava-se Fanon em 1956 no Congresso de Pensadores e Artistas Negros em Paris. E a resposta: 'todo homem negro (e aqui pensamos no amplo spectrum em que ele pode colocar-se ou ser colocado) tem em comum sua precária, sua inexprimível relação com o mundo branco. Fanon acrescenta: "sentimento de inferioridade? Não. Sentimento de inexistência”. ${ }^{17}$

\section{Ambivalência e racialização}

As razões que tornam insuportável ao "mulato" Eduardo de Oliveira e Oliveira viver em um mundo que o queria racialmente ambivalente são as mesmas que garantiriam existência confortável ao “judeu” Zweig, caso elas existissem na modernidade européia, ambiente do qual ele nunca desejou se retirar.

A lição histórica desses desencontros "civilizatórios" é que, em ambos os casos, a obsessão racial, quer para afirmar a existência de "raças" em sua 
pureza, taxonomia e rigidez, quer para afirmar a sua não-existência, anarquizando a exatidão das categorias binárias raciais que separam indivíduos ou grupos, encontra-se enraizada na mesma modernidade. Pode-se dizer, nessa perspectiva, que a modernidade inventa a taxonomia racial, tal como inventa o sujeito de sua perversão: o miscigenado, o ambivalente, o híbrido. Um não existe sem o outro. A obsessão racial é o que alimenta recorrentemente esse jogo. ${ }^{18}$

Os projetos modernos de engenharia social mobilizaram, ainda que em modos diferenciados, versões de sociedades futuras cujas utopias "raciais" dariam o tom de suas respectivas técnicas e planejamentos em direção à "boa sociedade" ou até mesmo à "boa civilização". Stefan Zweig pertencia, à sua revelia, a uma "raça" que fora sentenciada pelos nazistas ao isolamento e à morte sem que lhe fosse dada a alternativa de conversão à nacionalidade alemã, ao Geist do volk alemão, em sua "pureza" ariana. ${ }^{19} \mathrm{~A}$ recusa de pertencer a uma "raça" a ele destinada, ou seja, ser exclusivamente "judeu”, colocava Zweig, da perspectiva da "pureza" ariana, em um nãolugar "racial", vale dizer, lugar dos indefinidos, dos ambivalentes, dos híbridos, em contraste com as "raças legítimas", "apolíneas", cujo "valor" fundamental repousava na sentença da superioridade racial.

Se na Europa o ambivalente fica relegado ao limbo, no Brasil ocupa lugar legítimo. Entretanto, Eduardo de Oliveira e Oliveira se recusou a ocupar o lugar normalizado do miscigenado na "civilização mestiça". Nem sequer extraiu conforto dessa situação. Uma espécie de sensação de embaraço ético revela-se em seu trabalho quando reconhece ser o mulato um "constructo social", um híbrido, que reforça a reprodução da hierarquia social e das desigualdades raciais no Brasil. Ademais, o "mulato" desmobiliza o conflito ao "borrar" as "fronteiras" raciais e sociais entre os pólos "negro" e "branco", estes sim sociologicamente factíveis para Eduardo de Oliveira e Oliveira. ${ }^{20}$

O impacto muitas vezes trágico que a racialização e as raciologias tiveram para o destino de coletividades e de indivíduos cujas identidades expressariam em seus países de "origem" algum tipo de "ambivalência” (inadequação a lugares raciais definidos ou classificáveis conforme o padrão da cultura ou nação) parece ser uma das marcas perversas da modernidade ao 
longo de dois séculos: Escravidão, Jim Crow, Holocausto, Armênios, Tutsis, Apartheid. Eis algumas das tragédias dos racialismos.

O suicídio, nesse contexto, transmuta-se em alegoria da expressão subjetiva de autonomia da vontade, de fuga e de libertação perversa da "normalização racial" que assolou o ocidente nos últimos dois séculos. Não obstante, o revival da "raça" vem se revelando mais recentemente, nesse mesmo ocidente, pressuposto eficaz e legítimo de sujeitos de direitos em sociedades multirraciais. A luta pelo reconhecimento da "raça" como recurso de resgate de memória histórica e cultural de comunidades que se querem diferenciadas, mas também como categoria analítica, política e ética, impōe-se crescentemente no imaginário "pós-moderno" ${ }^{21}$

Trata-se, nesses novos tempos, de fértil emergência de comunidades de pertencimento que podem se autodefinir racialmente em modos essencialistas ou contingentes, transformando, com efeito, o espaço público espaço de visibilidade, de afirmação - em arena de "acerto de contas" com injustiças, exclusões e opressões do passado que se fundamentavam igualmente na "raça”. É como se pudéssemos já traçar, particularmente em relação às identidades "raciais", uma história da "metafísica racial”, como sugere Paul Gilroy, que vai do racismo biológico ao nacional, depois o cultural e mais recentemente o racialismo genótipo. ${ }^{22}$ Em nome dessa "metafísica racial" a modernidade ocidental tem capitulado de forma inescapável em mundo cuja ordem social pretende estar pautada por essencialismos, racialismos e pelos lugares fixos das identidades.

A pergunta que se segue a esse diagnóstico de obsessão racial que nasce com a modernidade ocidental é: em que medida os dilemas identitários da modernidade, em sua versão brasileira, expressariam uma dinâmica simbólica e social alternativas àqueles da modernidade dos contextos centrais?

\section{Nação, miscigenação e o conforto da ambivalência}

A década de 30 do século passado, sobretudo a partir do governo Vargas, promoveu um acerto de contas com diagnósticos contundentes, baseados em princípio racista, segundo os quais o estoque racial miscigenado do povo brasileiro tornava essa nação dos trópicos inviável devido à ausên- 
cia de uma integridade genética, vale dizer, racialmente ariana, que pudesse garantir o progresso intelectual e social do país.

Um contradiscurso que operaria em chave anti-racialista desloca da identidade racial para a identidade nacional as bases de refundação da nova nacionalidade brasileira. Nessa perspectiva, o passado deixaria de determinar a origem étnica ou racial dos que devem se integrar a essa nova nacionalidade e o futuro torna-se, com efeito, o lugar de uma brasilidade mestiça imune às ameaças de diferenciação, de segregação e, vale dizer, obsessivamente heterofóbica. ${ }^{23} \mathrm{O}$ mito da democracia racial, a brasilidade como congraçamento, como acolhimento e assimilação dos que desejam a ela se integrar e, ademais, o ideal universal de unidade do que originalmente é diverso, de inspiração iluminista, revelariam enorme eficácia simbólica no Brasil. ${ }^{24}$

Ainda que os ideólogos dessa nova nacionalidade utilizassem um léxico "racial" tão comum àquela conjuntura intelectual, o fundamento de suas teses é, em certo sentido, anti-racialista. Entretanto, a esse ideal de homogeneidade identitária não se seguiria necessariamente uma aposta na igualdade social, tampouco na quebra das hierarquias sociais. A indiferença moral e sociológica com os sujeitos da desigualdade social, muitos dos quais negros, não se traduziria necessariamente em mácula aos ideais dos que acreditavam ser o Brasil o país do futuro, vocacionado para uma verdadeira democracia racial. ${ }^{25}$

É neste cenário brasileiro de congraçamento identitário e de forte contraste social que o refugiado Zweig ingressa. E é este cenário que o surpreende. Como ele se considerava um estranho, um hóspede, sem lugar no mundo, o Brasil era apenas um lugar de repouso, um vislumbre de civilização futura, que ele julgava estaria livre das obsessões da modernidade européia, entre elas a obsessão racial. Para ele, o Brasil era "uma dádiva nesta nossa terra (...) único lugar onde não existe questão racial”. ${ }^{26}$

A condição ambivalente da qual Zweig não podia escapar em seu contexto de origem perderia no Brasil sua carga negativa a ponto de se recompor harmonicamente em uma nação dos trópicos pronta a anarquizar os imperativos das classificações raciais rígidas e impenetráveis. Contudo, esse "paraíso" terrestre, essa plasticidade "dionisíaca" não chegou a espantar seus demônios íntimos. Ele se mata no Brasil. 
O conforto da ambivalência identitária como importante substrato de uma identidade nacional simbolicamente acolhedora, para alguns um exemplo de tolerância e harmonia raciais, não seria objeto de intervenção sociológica até os anos $50 .{ }^{27}$ Entre as décadas de 40 e 50 , os aspectos ambivalentes do imaginário racial não significavam ainda um campo de disputas no cenário intelectual brasileiro. Nessas décadas afirmava-se ainda os aspectos singulares, por vezes ambíguos, das percepções raciais no Brasil, motivados, não raro, pela comparação com o dramático cenário das relações raciais nos EUA.

Gilberto Freyre, em seu ainda pouco explorado "Ordem e Progresso", 28 realiza uma pesquisa na qual aplica um questionário aberto que, em seus termos, seriam “'confissões' (...), na verdade bisbilhotices disfarçadas em investigação sociológica", ${ }^{29}$ de indivíduos nascidos entre as últimas décadas do século XIX e os nascidos no início do século XX, no sentido de

surpreender nos brasileiros da época sob análise, as relações da comunidade, urbana ou rural, em que nasceu ou cresceu o indivíduo, com o passado brasileiro, com o nacional, com a América, com a Europa, com o mundo contemporâneo; as relações entre o mundo pessoal e o impessoal dentro do qual se formou o mesmo indivíduo; sua simbiose com os espaços pelos quais se estendeu sua vida de brasileiro ou sua atividade ou sua imaginação, numa época de transição como foi em nosso País, o fim do século XIX alongado no princípio do $\mathrm{XX} .^{30}$

Nessa pesquisa, Freyre elabora um capítulo particular dedicado a surpreender as atitudes dos brasileiros de então com as "raças" diferentes da sua, pedindo a cada "autobiografado", como ele chama os entrevistados, que fixasse essa atitude. Eles em geral respondiam não "alimentar preconceito algum nem de raça, nem de cor”. Uma outra pergunta lhes era, então, dirigida: "como receberia o casamento de filho ou filha, de irmão ou de irmã, com pessoas de cor mais escura?” As repostas a essa segunda questão expressavam, ao contrário da primeira, sentimentos, segundo Freyre, fortemente "etnocêntricos" em face de uniões conjugais de filhos ou netos com pessoas de cor, por condição étnica mais do que cultural ou econômica. ${ }^{31}$

A ambivalência de atitudes e percepções relativas ao cenário racial presente na pesquisa realizada por Gilberto Freyre, em Ordem e Progresso, 
aliás de outro modo presente, sob a forma de etnografia histórica, em Casa grande \& senzala e em Sobrados e mucambos, não é, todavia, considerada por ele expressão de patologia, de incômodo ou mesmo de atraso. Ele vai ainda mais longe. A base de seu interesse para o entendimento da sociedade patriarcal e da transição desta para a sociedade "moderna" parece repousar exatamente nesse aspecto - a "ambivalência" — a tal ponto que a sua metodologia de pesquisa em Ordem e Progresso longe de desafiar a ambivalência, ajusta-se conscientemente a ela.

Daí, também, a quase nenhuma rigidez de fronteiras entre os próprios capítulos do ensaio quando se propõem, uns a surpreender do quase meio século de passado social de Brasil considerado nas suas páginas, as expressões de constância nesse passado, devorador de um futuro messiânico; outros os seus aspectos dinâmicos ou, no sentido apenas sociológico da palavra, progressivos. Relativamente progressivos. Sem que se atribua a tais aspectos a realização ou sequer a manifestação de um processo verdadeiramente messiânico de desenvolvimento nacional; ou exemplo do que um darwinista, aplicando marxistamente sua biologia à sociologia chamaria "evolução". ${ }^{32}$

A ambigüidade das atitudes e percepções dos brasileiros em face da questão racial revela-se em Freyre um habitus de nossa "civilização" que, longe de produzir soluções, sínteses ou superações temporais em registro teleológico, "esmera-se" em superpor diferentes temporalidades, diferentes tradições, diferentes atitudes e diferentes culturas em "equilibrada" articulação. Desde Casa grande \& senzala (1933), Gilberto Freyre já revelava a singularidade de sua abordagem acerca da formação social brasileira e das contribuições do português, do negro e do índio, abordagem na qual a obsessão com um futuro messiânico, com o progresso e com a civilização ocidental seria "substituída por uma interpretação que desse alguma atenção à híbrida e singular articulação de tradições". ${ }^{33}$ Pode-se dizer que, em sua abordagem, a afirmação de um Brasil e de uma identidade nacional, cujas características se mostram originais, ambivalentes e específicas, nutre-se de uma subentendida, quando não direta, comparação com os Estados Unidos.

Em Oracy Nogueira, ${ }^{34}$ a comparação com os Estados Unidos tornase explícita conforme "Relações raciais entre negros e brancos em São Paulo", ${ }^{35}$ trabalho apresentado no XXXI Congresso Internacional de Ameri- 
canistas, realizado em São Paulo, em 1954. Nesse trabalho, Oracy Nogueira cria uma tipologia pela qual é capaz de identificar os modos com os quais brasileiros e americanos exercitam diferentemente atitudes preconceituosas. Ele defende a tese de que "(...) embora, tanto nos Estados Unidos como no Brasil, não se possa negar a existência de preconceito racial, as diferenças que ocorrem nas respectivas manifestações são tais que se impõe o reconhecimento de uma diversidade quanto à natureza [e não quanto à intensidade]". ${ }^{36}$ Oracy Nogueira define o preconceito racial no Brasil como de marca, ou seja, "quando se exerce em relação à aparência, isto é, quando toma por pretexto para as suas manifestações os traços físicos do indivíduo, a fisionomia, os gestos, o sotaque". ${ }^{37}$ Já o preconceito racial nos EUA, Nogueira define como de origem, ou seja, "quando basta a suposição de que o indivíduo descende de certo grupo étnico, para que sofra as conseqüências do preconceito". ${ }^{38}$

Com efeito, o seu tratamento do preconceito de marca, quando contrastado ao preconceito de origem, acaba por ressaltar a natureza subjetiva, mediada, intermitente, miscigenada, estética, individual, circunstancial e de preterição social do negro, para o caso brasileiro, em contraposição à natureza rígida, racializada, de classificação racial implacável, de exclusão do negro, segregada, grupal, obsedante e emocional, para o caso norteamericano. Ao final, Oracy Nogueira conclui que o preconceito racial deve ser visto como "elemento cultural intimamente relacionado com o 'ethos' social, isto é, com o modo de ser culturalmente condicionado". ${ }^{39} \mathrm{O}$ acento na cultura, pode-se dizer, permite alguma relativização quanto à percepção do preconceito em perspectiva comparada. Neste caso, o desconforto com a ausência de um ponto de fuga "universal" não se manifesta em Oracy Nogueira.

A manifestação de desconforto sociológico com dualismos e ambivalências, quer do "sistema" de relações raciais, quer das atitudes "raciais", aparece de forma inaugural e, ademais, contundente, na sociologia de Florestan Fernandes. Para ele, “a confusão não procede do 'negro', mas das ambigüidades de nosso sistema de relações raciais e do próprio padrão assistemático, dissimulado e confluente, assumido pelo preconceito e pela discriminação raciais na sociedade brasileira". ${ }^{40}$ Florestan Fernandes inaugura- 
ria, por assim dizer, uma tradição de estudos raciais, segundo a qual a resolução dos dilemas sociais devido (a) às barreiras à incorporação da população de cor na ordem social competitiva e (b) às resistências em admitir-se o negro ou mulato em pé de igualdade com os brancos na sociedade brasileira" passariam a ser vigorosamente enfatizados, ${ }^{41}$ revelando seu incômodo com as ambigüidades das interações e representações raciais. Conforme Florestan Fernandes,

Enquanto tal dilema subsistisse, mesmo o padrão de democracia inerente à sociedade de classe numa economia capitalista seria impraticável. Ocorria uma perversão insidiosa do regime, que trazia consigo riscos potenciais para a diferenciação e o equilíbrio da ordem social competitiva. Enfrentar os dois dilemas era algo historicamente crucial, pois nenhuma sociedade pode ficar imune, indefinidamente, às conseqüências perturbadoras de inconsistências tão graves. ${ }^{42}$

\section{0 desconforto subjetivo da ambivalência}

Algumas décadas depois, esse Brasil é outro. De paraíso desracializado para alguns, transforma-se em inferno para outros. O Brasil da década de 1970 se encontrava sociologicamente desvendado. País do futuro era somente um label da ditadura militar. A modernização já havia deixado suas perversas pegadas. A desigualdade social não desaparece e se transfigura também em desigualdade racial, evidência dos diagnósticos estatísticos que associavam os não-brancos aos mais pobres na pirâmide social brasileira. ${ }^{43}$

Da democracia racial desmistificada emergiriam novos atores "raciais", cuja maior reinvindicação era a afirmação e valorização da negritude como fundamento na luta contra o racismo e contra a desigualdade racial. Renasce o Movimento Negro, cuja ênfase na diferenciação, na racialização, representaria uma ameaça real ao congraçamento da mistura. Nesse novo contexto de afirmação racial, o mulato, de ícone da brasilidade, de evidência a um só tempo real e simbólica da mistura, transforma-se no elemento desagregador que impede a luta dos negros em direção a uma visibilidade que estaria além dos tons cromáticos da pele. 
A condição ambivalente do mulato Eduardo de Oliveira e Oliveira é tudo o que ele quer negar. Em sua "reflexividade" racial, o mulato é o obstáculo epistemológico que impede que se veja o mundo tal como ele realmente deveria ser: preto e branco. $\mathrm{O}$ mulato é aquele que impede o acerto de contas com uma história de escravidão e opressão. $\mathrm{O}$ mulato desmobiliza e impede a consciência racial e desqualifica a necessária indignação moral contra o persistente racismo à brasileira.

Contudo, muito provavelmente, Eduardo de Oliveira e Oliveira, um de nossos personagens, encontraria hoje um Brasil mais próximo de suas pretensões. O Brasil de hoje vem alterando suas formas de perceber e tratar a dinâmica das relaçóes raciais. Hoje, as pesquisas de opinião revelam que os brasileiros ( $90 \%$ da população) reconhecem haver discriminação racial no Brasil; ${ }^{44}$ a denúncia pública do racismo não é apenas exceção; hoje, o governo assume haver discriminação racial no Brasil ${ }^{45}$; o Programa Nacional de Direitos Humanos reserva boa parte de suas cláusulas à discriminação racial e à promoção da população negra na sociedade; a linguagem da mídia, dos meios intelectuais, acadêmicos e culturais expressa-se sob o imperativo moral do "politicamente correto". Hoje, num certo sentido, o Brasil estranha a ambivalência identitária da sua modernidade e caminha em direção aos imperativos das rígidas classificações raciais. O desconforto com as ambigüidades do mundo social e mesmo com fenômenos que desafiam tanto o cartesianismo sociológico quanto as estatísticas ordenadoras de subjetividades, impõe-se efetivamente às agendas normativas da inteligentsia e dos movimentos sociais. Ilustro com um exemplo.

Em 1995, uma pesquisa de opinião realizada pelo Datafolha revelava o que seus formuladores consideraram uma incômoda contradição: 89\% dos brasileiros diziam haver racismo no país, mas só $10 \%$ admitiam ser eles próprios racistas. Denominado pelos formuladores da pesquisa como "racismo cordial", pois, "uma vez indagado se é racista, o brasileiro, cordialmente, nega", configurava-se, então, um desafio aos elaboradores da pesquisa: "retirar esse disfarce dos brasileiros". ${ }^{46}$

Para "desmascarar" os racistas não assumidos, os autores da pesquisa elaboraram 12 perguntas com o objetivo de saber o tamanho exato do racismo no Brasil, quem o exercia e de que forma. Criou-se então um ranking 
ou escala de preconceito, cujo objetivo era "atribuir pontos para as respostas dos entrevistados não-negros à doze perguntas." ${ }^{47}$ Chegava-se então aos seguintes números: $4 \%$ dos brasileiros poderiam ser considerados fortemente preconceituosos; $83 \%$ um pouco ou medianamente preconceituosos em relação aos negros; e 13\% apresentaram comportamento isento de preconceito contra os negros. Em números absolutos, concluía a pesquisa, "é correto dizer que há 80,8 milhões de preconceituosos adultos no país. Esse seria então "o número de potenciais racistas cordiais brasileiros com idade igual ou superior a 16 anos".$^{48}$ A precisão dos números, nesses termos, não poderia comportar qualquer paradoxo, qualquer resultado impreciso, qualquer contradição.

As trajetórias trágicas de nossos dois personagens no Brasil evidenciam diferentes sentimentos sobre a condição da ambivalência. Contudo, ela permanece sendo uma chave das mais sugestivas para se compreender o impacto que as cosmologias raciais modernas ainda hoje produzem nas formas como indívíduos e grupos desejam construir suas auto-representaçôes.

\section{Conclusão}

Este pequeno ensaio é apenas uma tentativa de trazer ao debate historiográfico o desafio de se enfrentar o fenômeno do racismo e dos racialismos constitutivos da modernidade através do imaginário racial brasileiro desde os anos 1930. Para este fim, sugeri que a apreensão da ambivalência identitária no Brasil vem se constituindo em importante alternativa para se compreender as especificidade da modernidade brasileira em face dos imperativos identitários da modernidade européia e norte-americana. Tentou-se mostrar que o conforto comparativo da condição ambivalente frente ao arianismo racial esgota-se quando ela é defrontada com os dilemas de integração dos negros na sociedade brasileira pós-emancipação.

De modo geral, pode-se dizer que o campo dos estudos históricos sobre racismo e relações raciais no Brasil pós-emancipação permanece ainda hoje aprisionado pela "herança da escravidão." As ciências sociais, sobretudo através dos trabalhos pioneiros de Carlos Hasenbalg e Nelson do Valle e Silva (1979, 1988 e 1992), vêm propondo uma dissociação estrutural en- 
tre escravidão e modernidade com implicações bastante sugestivas para o entendimento do fenômeno do racismo no Brasil. Já nas pesquisas históricas, as análises sobre as origens "escravistas" do racismo parecem abundantes se contrastadas com os estudos de como esse fenômeno se reproduziu historicamente na sociedade brasileira no pós-abolição, ou seja, com que novas representações, com que novas dinâmicas de interação.

Talvez o maior desafio que estudiosos da história social contemporânea enfrentem para a apreensão histórica do fenômeno do racismo seja o da própria naturalização social e cultural desse fenômeno. Sua expressão está de tal forma imbricada no processo mesmo de construção da identidade nacional, nos hábitos cotidianos e nas percepçôes ordinárias que o seu tratamento exigiria, não raro, um redobrado esforço de deslocamento epistemológico, de diálogos interdisciplinares e de criatividade metodológica. No Brasil o desafio é imenso. Tratar um fenômeno cuja expressão ambivalente muitas vezes convida o analista a sobrepor abordagens materialista e simbólica, individual e social, histórica, sociológica e antropológica reveste-se muitas vezes em um obstáculo a mais para o seu enfrentamento.

Por fim, o recurso à história comparada do fenômeno racista e racialista em diferentes contextos históricos da modernidade ocidental pode ser, com efeito, uma boa estratégia para desnaturalizar a própria reflexividade racial da historiografia brasileira.

\section{Notas}

${ }^{1}$ Zygmunt Bauman trata densamente esses dilemas identitários da modernidade européia. Ver Bauman, Zygmunt, Modernidade e ambivalência. Rio de Janeiro: Jorge Zahar Editor, 1999.

${ }^{2} \mathrm{O}$ impacto da modernidade para os judeus europeus e para a chamada diáspora negra não se constitui ainda em objeto de diálogos sistemáticos entre estudiosos desses dois grupos. Paul Gilroy tem chamado a atenção para a importância crucial desse diálogo, especialmente para uma melhor compreensão da dimensão trágica da modernidade, tanto para judeus quanto para negros. Gilroy, Paul. The black Atlantic: modernity e double consciousness. Cambridge: Harvard University Press, 1993. p. 47. Esse diálogo nos Estados Unidos parece mais evidente. Neste caso, ver Lerner, Michael. West, Cornel. jews and blacks: a dialogue on race, religion and culture in America. New York: Plume, 1996; Salzman, Jack, West, Cornel (Eds). Struggles in the promised land: toward a history of black-jewish relations in the United States. Oxford: Oxford University Press, 1997. 
${ }^{3}$ Os anos trinta são considerados, sobretudo a partir da obra de Gilberto Freyre, um divisor de águas entre uma versão pessimista sobre as possibilidades civilizatórias da nação brasileira, cujo estoque racial, ademais miscigenado, a tornava inviável e estéril, e uma outra, que, partindo justamente da constatação da miscigenação racial, vislumbraria de modo otimista um processo civilizatório autêntico e alternativo para a nação brasileira. Ver Skidmore, Thomas. Black into white: race and nationality in Brazilian thought. London: Duke University Press, 1993; Araújo, Ricardo Benzaquen. Guerra e paz, Casa grande \& senzala e a obra de Gilberto Freyre nos anos 30. Rio de Janeiro: Editora 34, 1994; Schwartz, Lilia. O espetáculo das raças: cientistas, instituições e questão racial no Brasil, 1870-1930. São Paulo: Companhia das Letras, 1993.

${ }^{4}$ Cf. Gilsoy, Paul. Op. cit. Gilroy, Paul. Race ends here. Ethnic and Racial Studies, Special Issue, v. 21, n.1, pp. 838-847, 1998; Appiah, Kwane A. Na casa de meu pai: a África na Filosofia da Cultura. Rio de Janeiro: Contraponto, 1997; West, Cornell. Race matters. New York: Vintage Books, 1993; Birnbaum, Pierre and Katznelson, Ira (Eds.). Paths of emancipation: Jews, states, and citizenship. Princeton: Princeton University Press, 1995; Anderson, Benedict. Imagined communities: reflections on the origin and spread of nationalism. Revised edition. London: Verso, [1983], 1994. Galchinsky, M. e Heschel, S. Insider/outsider: American Jews and multiculturalism. Berkeley: University of California Press, 1998. As contribuições das Ciências Sociais para o tratamento do fenômeno racial como constitutivo da modernidade têm sido mais freqüentes. A pesquisa histórica, de um modo geral, não tem promovido debates desvinculados do mainstream dos estudos sobre escravidão. Quanto aos estudos históricos sobre racismo nos EUA, ver Holt, Thomas. Explaining racism in American History. In Molho, Anthony, Wood, Gordon (Eds.). Imagined histories. Princeton: Princeton University Press, 1998, pp. 107-119.

${ }^{5}$ Embora o suicídio de Stefan Zweig e de sua mulher, Elisabeth Charlotte Altmann Zweig, sugira uma espécie de pacto de morte do casal, nenhuma linha ou carta foi deixada por ela. Na declaração deixada por Zweig, nenhuma referência ao suicídio da mulher. Como chama a atenção Spitzer em seu Lives in between, ela permaneceu até na morte uma "mulher silenciosa". Cf. Spitzer, Leo. Lives in between: assimilation and marginality in Austria, Brazil, West Africa 1780-1945. Cambridge: Cambridge University Press, 1989 e Dines, Alberto. Morte no paraíso: a tragédia de Stefan Zweig. Rio de Janeiro: Nova Fronteira, 1981. Há um mal-estar relativo ao significado moral do suicídio de judeus, vítimas do nazismo. Thomas Mann teria dito sobre o suicídio de Stefan Zweig, "Could he concede the archenemy such a triumph?". Hannah Arendt considerava o suicidio dos refugiados do nazismo como "abnormally asocial and unconcerned about general events", exemplos de insensível "kind of selfishness". Como se considerasse esse tipo de suicídio imoral, ela escreve em We refugee": "We are the first non-religious Jews persecuted and we are the first one who, not only in extremis, answer with suicide". Hannah Arendt. We Refugees. In . The Jew as pariah. New York: Grove Press, 1944, pp. 58-60.

${ }^{6}$ Conta-se que esse livro teria sido sugerido por Getúlio Vargas, numa espécie de troca pela permanência do escritor no Brasil. Seus biógrafos, contudo, negam essa versão. Ver Dines, Alberto. Op.cit. 
${ }^{7}$ Zweig, Stefan. Brasil: pais do Futuro. Rio de Janeiro: Edit. Guanabara, 1941, pp. 231232.

${ }^{8}$ Do círculo de amigos de Stefan Zweig que viviam na Europa central e escolheram o suicídio como "solução final" para a perseguição nazista da qual eram vítimas preferenciais, temos: Egon Friedell, Otto Pick, Ernst Weiss entre outros. Os números relativos a suicídios de judeus na Europa antes e durante a Grande Guerra são bastante reveladores. Segundo Lucy Dawidowicz, "Among some Jews who had stacked their whole existence on identity with Germany, despair led to suicide. Between 1932 and 1934, nearly 350 Jews commited suicide, a rate 50 percent higher than in the rest of the population." Depois da famosa Kristallnacht em 1938, conta-nos Hannah Arendt, "suicides accounted for more than half the Jewish burials”, cf. Dawidowicz, Lucy. The war against the Jews, 1933-1945. New York: Holt, Rinehart and Winston, 1975. pp. 232, 264 e 292 e Arendt, Hannah. The Jews as pariah. New York: Grove Press, 1978. pp. 58-59 apud Spitzer, Leo. Lives in between. Op. cit., p. 236.

${ }_{9}^{9}$ Apud Spitzer, Leo. Vidas de entremeio. Rio de Janeiro: Editora da Universidade do Estado do Rio de Janeiro, 2001, p.195.

${ }^{10}$ Peter Fry relatou-me a história trágica desse professor de sociologia da Universidade de São Carlos e estudante de Otávio Ianni na USP, a quem ele havia conhecido na década de 70. Em nossas conversas, Peter Fry lembraria o crescente afastamento dos amigos de Eduardo de Oliveira (seu verdadeiro nome) diante de sua obsessão pela má consciência dos que não assumiam a "raça" como identidade.

${ }^{11}$ Baseio-me em depoimentos de Peter Fry e José de Souza Martins que conheceram mais diretamente Eduardo de Oliveira e Oliveira. Saliento, todavia, que a referência à Eduardo de Oliveira e Oliveira não tem pretensōes de resgate biográfico. A referência a seu suicídio é de ordem simbólica. Interpreto-o, livremente, como exemplo trágico em mundo de obsessão racial. Não me ocupo em desvendar as "reais" razões de seu suicídio. O desconforto com a mulatice que busco explorar aqui em dimensão subjetiva me é sugerido por seu texto "O mulato: um obstáculo epistemológico". Argumento, jan., 1974.

${ }^{12}$ Um modesto acervo que reúne cartas, alguns escritos acadêmicos, peças de teatro e objetos está na Universidade Federal de São Carlos.

${ }^{13}$ Depoimento de José de Souza Martins, amigo e contemporâneo na USP de Eduardo de Oliveira e Oliveira.

${ }^{14}$ Eduardo de Oliveira e Oliveira. O mulato: um obstáculo epistemológico. Argumento, jan. 1974.

${ }^{15}$ Degler, Carl. Neither black, nor white: slave and race relations in Brazil and the United State. Madison: The University of Wisconsin Press, 1971.

${ }^{16}$ Franz Fanon (1925-1961), psicanalista e filósofo social, nasceu na Martinica, estudou na França e trabalhou em vários países na África. Fortemente influenciado por J. P. Sartre e Aimé Césaire, Fanon é mais conhecido por seus escritos sobre racismo e colonialismo. Seus trabalhos mais conhecidos são Peau noire, masques blancs, de 1952, e Les damnés de la terre, de 1961. 
${ }^{17}$ Oliveira, Eduardo de Oliveira e. O mulato: um obstáculo epistemológico. Argumento, jan. de 1974, p. 73.

${ }^{18}$ Bauman, Zygmunt. Modernidade e ambivalência. Rio de Janeiro: Jorge Zahar, 1999. 19 . Modernidade e holocausto. Rio de Janeiro: Jorge Zahar, 1998, p. 88.

${ }^{20}$ Oliveira, Eduardo de Oliveira e. Op. cit.

${ }^{21}$ Taylor, Charles. Multiculturalism: examining the politics of recognition. New Jersey: Princeton University Press, 1994; Gilroy, Paul. The black Atlantic: modernity and double consciousness. Cambridge: MA, Harvard University Press, 1993.

${ }^{22}$ Gilroy, Paul Race ends here. Ethnic and Racial Studies, Special Issue, v. 21, n.1, pp. 838847, 1998.

${ }^{23}$ Costa, Sérgio. A construção sociológica da raça no Brasil. 2001 (mimeo).

${ }^{24}$ Sérgio Costa resume apropriadamente esse ponto: "Parece evidente que o desejo de sobrepor a força do progresso sobre o passado opressivo e a construção de uma identidade voltada para o futuro próprios ao iluminismo francês e não a ênfase na ancestralidade comum dos românticos alemães que marcam a reconfiguração da nação brasileira a partir dos anos 30". Idem, p. 7.

${ }^{25} \mathrm{Idem}$.

${ }^{26}$ Carta a Friderike Zweig de 26 de agosto de 1936. In Zweig, Stefan and Friderik. Their correspondence, 1912-1942. Nova York, 1954. p. 290 apud Spitzer, Leo. Op. cit., p.194.

${ }^{27} \mathrm{O}$ programa de pesquisas sobre relaçōes raciais no Brasil, patrocinado pela Unesco nos anos 50, pode ser considerado um marco de desconstrução de um Brasil ainda auto-indulgente com sua dinâmica de relaçôes raciais. Sobre esse tema, ver Maio, Marcos Chor. O Projeto Unesco e a Agenda das Ciências Sociais no Brasil dos anos 40 e 50. Revista Brasileira de Ciências Sociais, vol. 14, n. 41, out. 1999.

${ }^{28}$ A obra de Gilberto Freyre, Ordem e Progresso (1959), escrita no final da década de 50, é, segundo o autor, parte da trilogia que começa com Casa grande \& senzala (1933) e continua em Sobrados \& mocambos (1936). O trabalho que ele não pôde completar, e que seria também incluído é Covas rasas \&̋ jazigos.

${ }^{29}$ Freyre, Gilberto. Ordem e progresso. Rio de Janeiro: José Olympio. 1959, p. xxi.

${ }^{30}$ Idem. p. xxx-xxxi.

${ }^{31}$ O capítulo "A República de 89 e o progresso da miscigenação no Brasil", de Ordem e progresso, é o que trata mais diretamente essa questão.

${ }^{32}$ Freyre, Gilberto. Op. cit., p. xxiv.

${ }^{33}$ Araújo, Ricardo Benzaquen. Op. cit., p. 30.

${ }^{34}$ Oracy Nogueira (1917-1996), antropólogo, aluno de Donald Pierson na Escola Livre de Sociologia e Política de São Paulo e doutor pela Universidade de Chicago. Participou da pesquisa da Unesco no início dos anos 50. Seu acervo encontra-se hoje no IFCS/UFRJ. ${ }^{35}$ Nogueira, Oracy. Preconceito racial de marca e preconceito racial de origem. Anhembi, 1955. p. 195. 
${ }^{36}$ Idem, p. 284.

${ }^{37}$ Idem, p. 285.

${ }^{38}$ Idem, p. 285.

${ }^{39}$ Idem, p. 298.

${ }^{40}$ Fernandes, Florestan. A integração do negro na sociedade de classes. 3. ed. São Paulo: Ática, 1978, p. 408.

${ }^{41}$ Embora Discriminação e desigualdades raciais, de Carlos Hasenbalg, represente um momento de inflexão na historiografia dos estudos raciais por sua discordância de Florestan Fernandes quanto ao preconecito racial como resquício da escravidão, em outra perspectiva eles partilham a mesma aversão ao que consideram o culturalismo freyreano. Ver Hasenbalg, Carlos. Discriminação e desigualdades raciais. Rio de Janeiro: Graal, 1979.

${ }^{42}$ Fernandes, Florestan. Op. cit., p. 7.

${ }^{43}$ Ver Hasenbalg, Carlos, Silva, Nelson do Valle. Estrutura social, mobilidade e raça. São Paulo: Vértice/Iuperj, 1988.

${ }^{44}$ Turra, Cleusa, Venturi, Gustavo. Racismo cordial. Folha de S. Paulo/Datafolha. São Paulo: Ática, 1995.

${ }^{45}$ Cardoso, Fernando Henrique. Construindo a democracia racial. Brasília: Presidência da República, 1998.

${ }^{46}$ Turra, Cleusa, Venturi, Gustavo. Op. cit., p. 13.

${ }^{47}$ As 12 perguntas elaboradas eram: "Eu vou dizer algumas coisas que as pessoas costumam falar e gostaria que você dissesse se concorda ou discorda de cada uma, totalmente ou em parte: 1) "negro bom é negro de alma branca"; 2) "uma coisa boa do povo brasileiro é a mistura de raças"; 3) "as únicas coisas que negros sabem fazer bem são músicas e esportes"; 4) "toda raça tem gente boa e gente ruim, isso nao depende da cor da pele; 5) "negro, quando não faz besteira na entrada, faz na saída"; 6) "se pudessem comer bem e estudar, os negros teriam sucesso em qualquer profissão"; 7) "se Deus fez raças diferentes, é para que elas não se misturem"; 8) "alguns estudos recentes afirmam que, por natureza, negros e brancos são diferentes em relação ao nível de inteligência. Na sua opinião existem diferenças de inteligência entre brancos e negros? Se sim de modo geral, quem são mais inteligentes os brancos ou negros?" 9) "você votaria ou já votou alguma vez em um político negro?" 10) "se no seu trabalho você tivesse um chefe negro, você não se importaria; ficaraia contrariado, mas procuraria aceitar; ou não aceitaria e mudaria de trabalho?" 11) "se várias famílias negras fossem morar em sua vizinhança, você não se importaria; ficaria contrariado, mas procuraria aceitar; ou não aceitaria e mudaria de casa?” 12) "e se um filho ou uma filha sua se casasse com uma pessoa negra, você não se importaria; ficaria contrariado, mas procuraria aceitar; ou não aceitaria o casamento?”

${ }^{48}$ Turra, Cleusa, Venturi, Gustavo. Op. cit., p. 17. 


\section{Resumo}

O objetivo deste ensaio é trazer ao debate historiográfico o desafio de se enfrentar o tema do racismo e dos racialismos constitutivos da modernidade através do imaginário racial brasileiro, desde os anos 1930. Para este fim, sugiro que a apreensão da ambivalência identitária no Brasil vem se constituindo em importante alternativa para se compreender as especificidades da modernidade brasileira em face dos imperativos identitários da modernidade européia e norte-americana. Pretende-se mostrar, através de dois personagens suicidas, o "judeu" Stefan Zweig e o "mulato" Eduardo de Oliveira e Oliveira, os paradoxos da construção e da representação de identidades étnico-raciais na modernidade brasileira.

\section{Abstract}

The aim of this essay is to bring into the historiographical debate the issues of ambivalence and racialism which are a constitutive part of Brazil's racial imaginary since the 1930's. Bearing this in mind I propose that Brazilian identitary ambivalence is an alternative tool to face European and North-American models of modern identity. Nevertheless, the Brazilian racial ambivalence finds its limits when confronted with the dilemmas of integration of black Brazilians after their emancipation. We aim to show it, through a comparative analysus of two historical figures, the "jew" Stefan Zweig and the "mulato" Eduardo de Oliveira e Oliveira, as examples of the paradoxal condition of Brazilian racial identity. 